\title{
Tumor mixto de células germinales de la glándula pineal
}

\section{Pineal Gland Germ Cell Mixt Tumor}

\author{
Federico Avondet ${ }^{1}$ Federico Cabo ${ }^{1}$ Matías Negrotto ${ }^{2}$ Dardo Centurión ${ }^{3}$
}

1 Departamento de Imagenología, Hospital de Clínicas “Dr. Manuel Quintela," Montevideo, Uruguay

2 Departamento de Imagenología, Hospital Maciel, Montevideo, Uruguay

${ }^{3}$ Departamento de Anatomía Patológica del Hospital de Clínicas “Dr. Manuel Quintela," Montevideo, Uruguay

Rev Argent Radiol 2018;82:144-147.

Estimados Editores,

Los tumores de células germinales intracraneales constituyen un grupo propio de tumores, homólogos a los que se desarrollan en las gónadas. Con la excepción de los germinomas o teratomas puros, el resto son mixtos en su composición histológica. ${ }^{1}$ Pueden contener en diferentes combinaciones, germinoma, teratoma (maduro o inmaduro), tumor del saco vitelino, carcinoma embrionario y/o coriocarcinoma. ${ }^{2}$

Se presenta el caso clínico de un varón de 20 años, sin antecedentes personales, que consultó por cefalea holocraneana de un mes de evolución, progresiva, sin respuesta a analgésicos y diplopía. El examen físico y los exámenes de laboratorio de rutina resultaron normales.

Se realizó tomografía computada de cráneo (TC) (- Fig. 1), donde se constató la presencia de un proceso expansivo sólido con epicentro en la glándula pineal, bien delimitado, levemente hiperdenso en TC sin contraste, con una única calcificación de distribución periférica. Determinó efecto de masa locoregional, comprimiendo el mesencéfalo, el tercer ventrículo y el acueducto de Silvio, generando dilatación del sistema ventricular supratentorial.

Se realizó una derivación ventrículo peritoneal de urgencia. Se solicitó resonancia magnética (RM) (-Fig. 1), que evidenció una lesión hipointensa en ponderación T1, heterogénea en ponderación $\mathrm{T} 2$, con realce intenso y levemente heterogéneo tras la administración de contraste, en función del componente quístico observado en ponderación T2.

Se dosificó la alfafetoproteína (AFP)y gonadotrofina coriónica humana ( $\beta$-HCG) en sangre y líquido cefalorraquídeo (LCR), con valores en LCR positivos de $60,5 \mathrm{ng} / \mathrm{ml} \mathrm{y} 0,993 \mathrm{mUI} / \mathrm{ml}$, y en

received

June 29, 2017

accepted

November 29, 2017

published online

March 23, 2018
Address for correspondence Federico Avondet, Departamento de Imagenología, Hospital de Clínicas "Dr. Manuel Quintela”,

Montevideo, Uruguay (e-mail: federicoavondet@gmail.com).

sangre de $1128 \mathrm{ng} / \mathrm{ml} \mathrm{y} 1,0 \mathrm{mUI} / \mathrm{ml}$ respectivamente. Se realizó biopsia quirúrgica (-Fig. 2) con abordaje infratentorial supracerebelar.

El estudio histológico mostró una proliferación celular de la línea germinal, con dos componentes: uno mayoritario (60\%) correspondiente a un componente germinomatoso y otro minoritario ( $40 \%$ ) correspondiente a un componente no germinomatoso, de tipo teratoma inmaduro ( - Fig. $3 \mathbf{A}$ ). La inmunohistoquímica mostró intensa positividad para CD 117 para el componente germinomatoso (-Fig. 3B), citoqueratina intensamente positivo en los focos tubulares ( - Fig. 3C), con negatividad para sinaptofisina ( - Fig. 3D) y cromogranina (excluye tumores neuro-endocrinos).

La citología del LCR y la RM de columna no presentaron elementos de diseminación leptomeníngea. El paciente presentó empeoramiento clínico en relación al sangrado intratumoral posterior a la biopsia (-Fig. 4A). Con el diagnóstico de tumor mixto de células germinales (TMCG) se inició un tratamiento en base a radioterapia estereotáxica fraccionada (RTEF) con buena respuesta clínicoimagenológica ( $\mathbf{F i g . ~ 4 B ) . ~}$

La incidencia real de tumores de células germinales pineales, y en particular la variedad mixta, es desconocida. Revisiones de base de datos, reportan una incidencia de 53\% de tumores de células germinales, con franca predominancia masculina y una media de edad entre los 10 y los 20 años. De todos ellos, el $80 \%$ corresponden a germinomas y el $20 \%$ restante se dividen entre teratomas, tumores mixtos y otras variedades menos frecuentes (no germinomatosos). ${ }^{1}$

Las células germinales son células pluripotenciales, con capacidad para diferenciarse en cualquier tipo celular.
Copyright (c) 2019, Sociedad Argentina de Radiología. Publicado por Thieme Revinter Publicações Ltda., Rio de Janeiro, Brazil. Todos los derechos reservados.

\section{License terms}

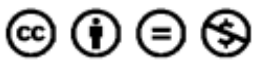

$10.1055 / \mathrm{s}-0038-1639495$ ISSN 1852-9992. 

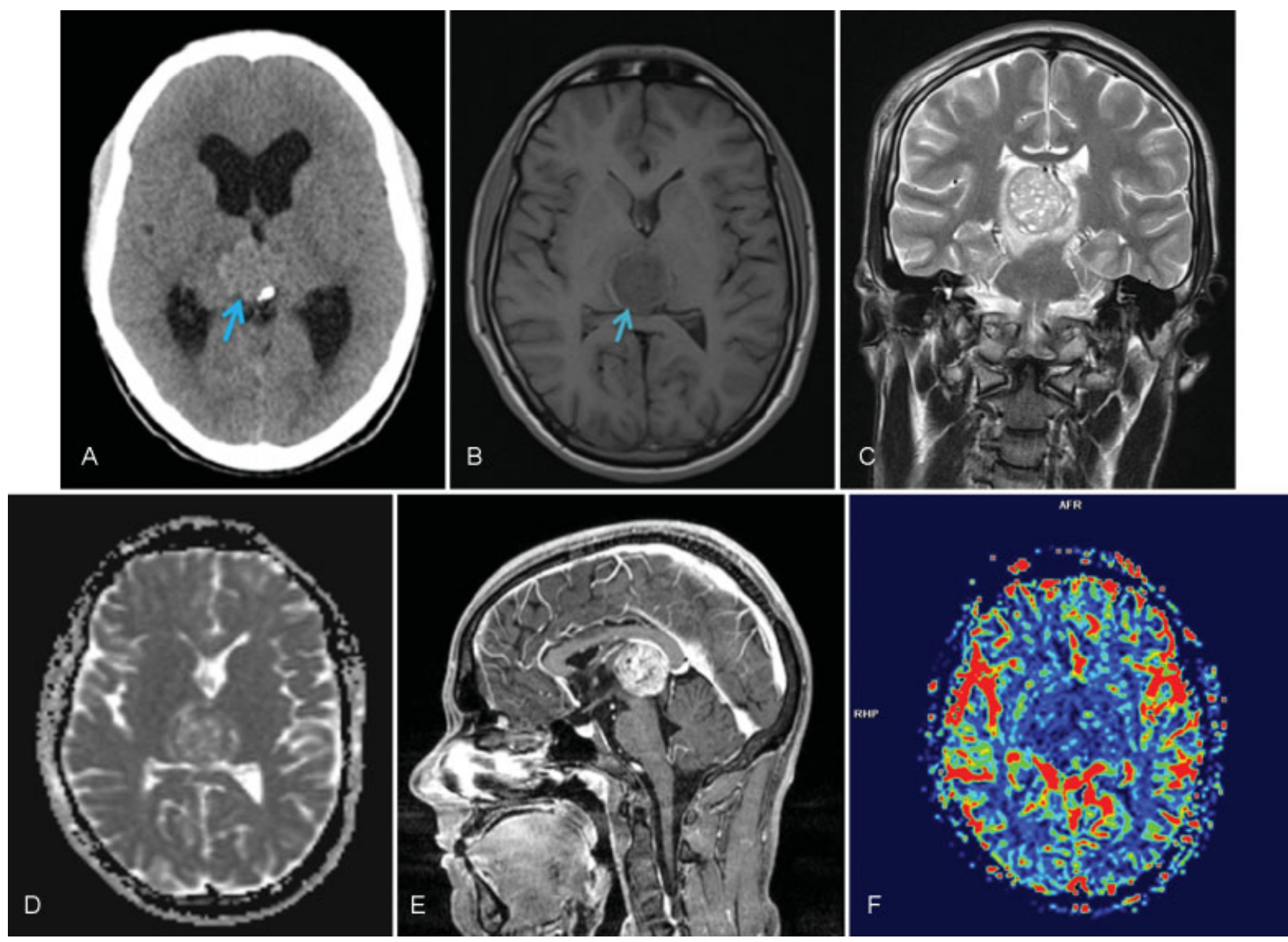

Fig. 1 Lesión hiperdensa con calcificación periférica en tomografía computada (TC) sin contraste (A). En resonancia magnética (RM) es hipointensa en ponderación T1 (B), heterogénea en ponderación T2 (C), con leve restricción en coeficiente aparente de difusión (ADC) (D). Se aprecia realce intenso y levemente heterogéneo con Gadolinio y desplazamiento superior de las venas cerebrales internas (E). No presenta aumento del volumen sanguíneo cerebral con técnica de perfusión (F).

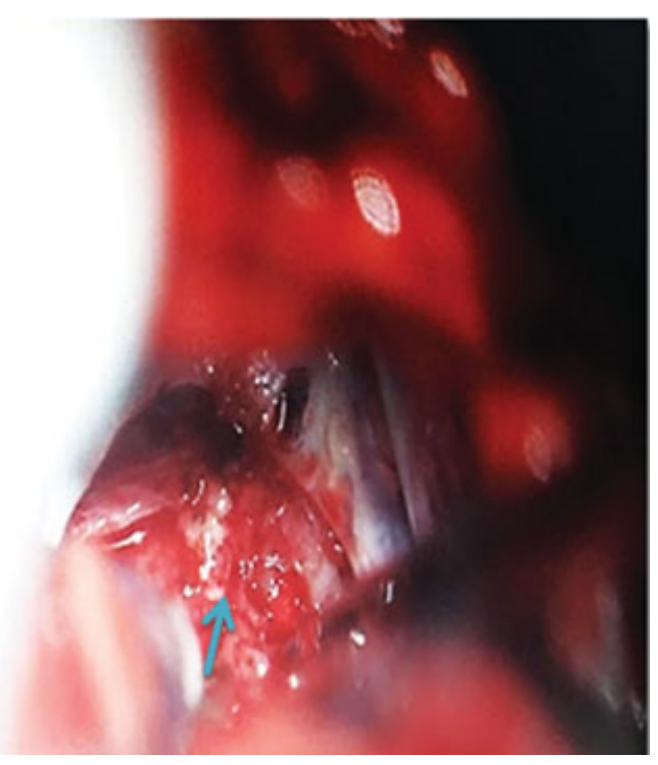

Fig. 2 Foto del intraoperatorio. Abordaje supracerebelar infratentorial. Se reconoce la tumoración roja grisácea (flecha).
Aparecen sobre la quinta semana embrionaria en el saco vitelino y migran hacia los testículos o los ovarios. La migración incorrecta y anidación posterior, inhibiría la apoptosis de las células ectópicas, siendo el sustrato para la posterior aparición de tumores de células germinales extragonadales. $^{3}$

Dada la región anatómica que ocupan y en función de su tamaño, tienden a presentarse con hidrocefalia, y menos frecuentemente, con trastornos oculomotores por compresión de núcleos mesencefálicos (síndrome de Parinaud) y/o ataxia. ${ }^{4,5}$

Es importante hacer la distinción entre germinoma y tumores no germinomatosos, con diferencias sustanciales en el tratamiento, sobre todo en término de campo y dosis de radiación, papel de la quimioterapia y rol de la cirugía. Los tumores no germinomatosos requieren un enfoque terapéutico más agresivo, mientras los germinomas puros responden bien a la radioterapia. ${ }^{4,6}$

Ciertas células germinales producen marcadores tumorales, como AFP, $\beta$-HCG y fosfatasa alcalina placentaria (FAP), que pueden dosificarse en LCR y en sangre. Los TMCG pueden ser productores tanto de AFP, $\beta$-HCG y FAP, mientras los germinomas puros solo serían potenciales productores de FAP. ${ }^{4,5,7}$ 


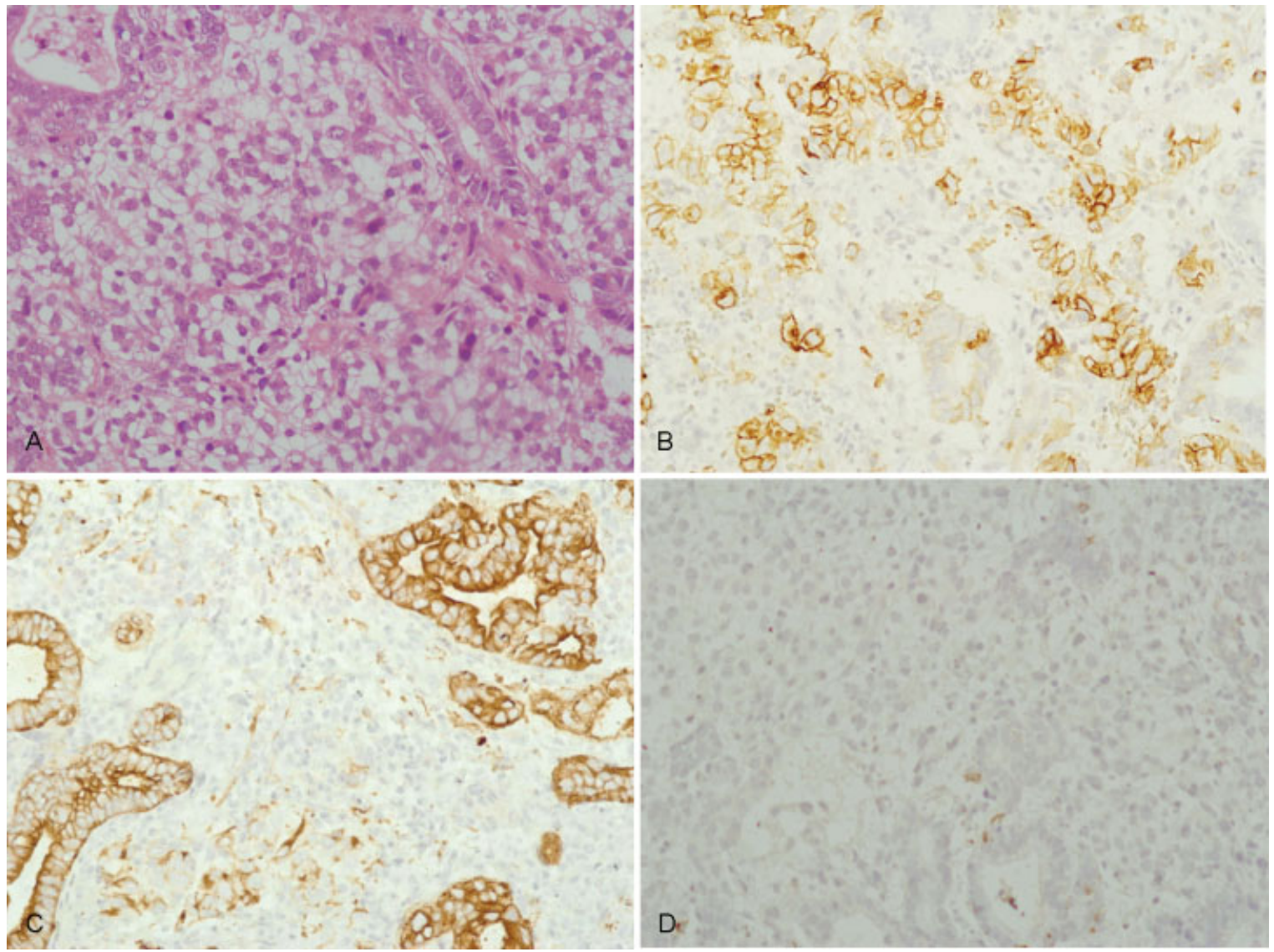

Fig. 3 Histopatología del paciente. (A) Componente germinomatoso predominante y componente no germinomatoso, de tipo teratoma inmaduro, representado por estructuras tubulares (HE 10x). (B) CD 117 positivo en células del germinoma (Inmunohistoquímica 10x). (C) Citoqueratina Cocktel positiva en componente tubular teratomatoso (Inmunohistoquímica 10x). (D) Sinaptofisina totalmente negativa en estructuras tubulares y componente germinomatoso.

No hay características imagenológicas patognomónicas, limitando el diagnóstico de certeza, siendo necesaria la medición de marcadores tumorales y en un altísimo porcentaje de casos, la confirmación histológica. A eso se suma, el amplio solapamiento en cuanto a la neuroimagen

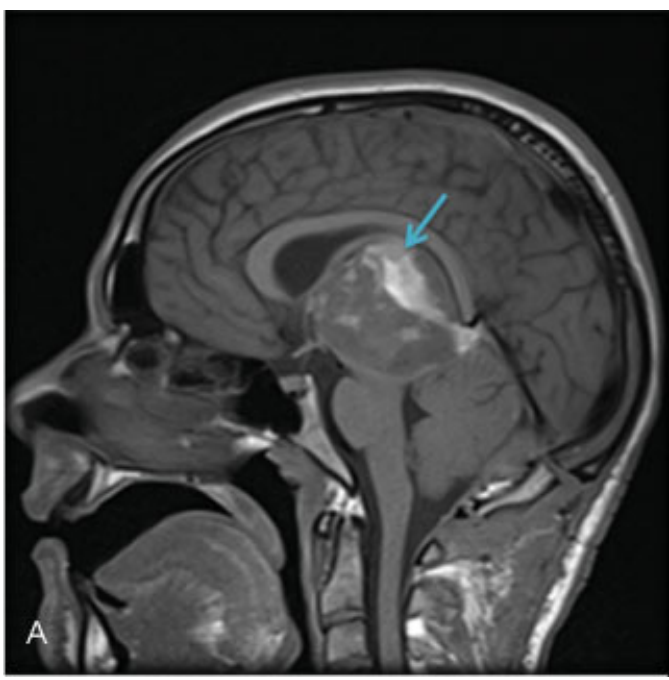

con otros tumores pineales como los pineocitomas, pineoblastomas o gliomas. ${ }^{4}$

En tomografía son lesiones sólidas, bien delimitadas, hiperdensas en el estudio sin contraste, que realzan ávidamente y de manera homogénea con el medio de

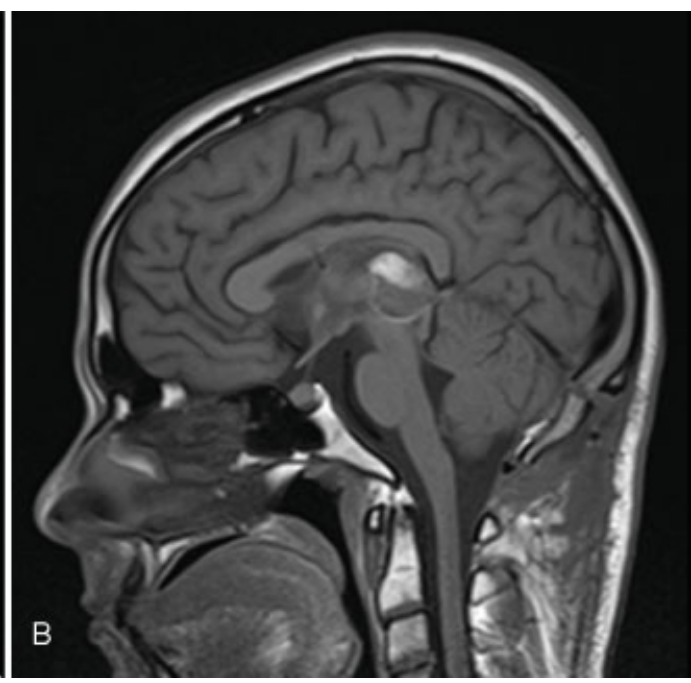

Fig. 4 RM Sagital ponderada en T1. (A) Previo al inicio de la radioterapia estereotáxica fraccionada (RTEF). Se observa aumento del tamaño tumoral con respecto a estudio inicial, en relación a hemorragia intratumoral post biopsia (flecha). (B) Luego de completar 20 sesiones de RTEF. Se observa franca disminución del tamaño tumoral. 
contraste. Algunos TMCG tienden a presentar un realce más heterogéneo, aunque no es un hallazgo patognomónico. ${ }^{8}$ Una forma de diferenciar los tumores del parénquima pineal de las neoplasias de células germinales, se basa en que los primeros tienden a crecer obliterando la arquitectura pineal y desplazando las calcificaciones hacia la periferia ("imagen en estallido"), mientras los segundos tienden a envolverlas. ${ }^{5}$

En RM son generalmente hipointensos en ponderación T1, heterogéneos en ponderación T2 y pueden presentar restricción en difusión dada su alta celularidad. ${ }^{5}$ No hay reportes en la literatura en cuanto al uso de técnicas funcionales para los tumores pineales. De existir componente teratomatoso puede observarse alta señal en ponderaciones T1 y T2 por la presencia de grasa y en los coriocarcinomas alta señal en ponderación T1 por sangrado intratumoral. $^{9}$

Confidencialidad de los datos

Los autores declaran que han seguido los protocolos de su centro de trabajo sobre la publicación de datos de pacientes y que todos los pacientes incluidos en el estudio han recibido información suficiente y han dado su consentimiento informado por escrito para participar en dicho estudio.

\section{Conflicto de Intereses}

Los autores del trabajo declaran no tener ningún conflicto de intereses.

\section{Bibliografía}

1 Villano JL, Propp JM, Porter KR, et al. Malignant pineal germ-cell tumors: an analysis of cases from three tumor registries. Neurooncol 2008;10(02):121-130

2 Shuster A, Al-Attar H, Midia M. Case of the month \#172: pineal mixed germ cell tumour with obvious teratomatous and "harbored" germinomatous components. Can Assoc Radiol J 2011;62(04):299-301

3 UenoT, Tanaka YO, Nagata M, et al. Spectrum of germ cell tumors: from head to toe. Radiographics 2004;24(02):387-404

4 Packer RJ, Cohen BH, Cooney K. Intracranial germ cell tumors. Oncologist 2000;5(04):312-320

5 Smith AB, Rushing EJ, Smirniotopoulos JG. From the archives of the AFIP: lesions of the pineal region: radiologic-pathologic correlation. Radiographics 2010;30(07):2001-2020

6 Aizer AA, Sethi RV, Hedley-Whyte ET, et al. Bifocal intracranial tumors of nongerminomatous germ cell etiology: diagnostic and therapeutic implications. Neuro-oncol 2013;15(07):955-960

7 Calles Blanco C, Guzman de Villoria JA. Lesions of the Pineal Region: A Practical Approach. Educational Exhibit. Electronic Presentation Online System. Eur Soc Radiol 1594;10:C0937

8 Sato K, Takeuchi H, Kubota T. Pathology of intracranial germ cell tumors. Prog Neurol Surg 2009;23:59-75

9 Fang AS, Meyers SP. Magnetic resonance imaging of pineal region tumours. Insights Imaging 2013;4(03):369-382 